\title{
The Party-Line Pandemic: A Closer Look at the Partisan Response to COVID-19
}

John F. Camobreco, Christopher Newport University, USA

Zhaochen He, Christopher Newport University, USA

ABSTRACT The response to the coronavirus pandemic in the United States has shown that even a serious public health crisis cannot escape the lens of partisanship. The literature shows that most Republicans have viewed the coronavirus as less serious than their Democratic counterparts. This study demonstrates that this partisan gap extends to the real behavior of the public during, and after, the coronavirus state lockdowns. Using location data from mobile phones, we find that county-level partisanship predicts compliance with state shutdown orders, even when controlling for local COVID-19 intensity. Further, the magnitude of this effect is stronger than that of other explanatory variables, such as age, education, and population density. These results show that partisan beliefs can affect behavior regarding issues that are not overtly political, even behaviors that could put one or others at risk.

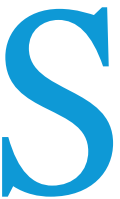

cholars have long been aware that party identification is a strong predictor of numerous political attitudes and behaviors (Green, Palmquist, and Schickler 2002). But is party identification powerful enough to overcome objective advice from public health experts, even if doing so could prove to be dangerous? The evidence that we present about the coronavirus pandemic suggests that party identification indeed has this power. This article quantifies the degree to which political affiliation drove not only the policy response to COVID-19 but also individual compliance with those policies. We show that partisanship remains significant even after controlling for the local severity of the coronavirus pandemic, as well as other factors that might have influenced mobility and social distancing. These findings lend credence to the idea that partisanship is a strong driver of individual attitudes and behaviors about a serious issue that, on its face, is not political.

\section{LITERATURE}

A growing body of research demonstrates the effect of partisanship toward all matters related to the coronavirus pandemic. The evidence shows that Republicans view the pandemic as being much less severe than Democrats (Funk and Tyson 2020), and that

John F. Camobreco $(\mathbb{D})$ is associate professor of political science at Christopher Newport University. He can be reached at camobrec@cnu.edu.

Zhaochen $\mathrm{He}(\mathbb{D}$ is assistant professor of economics at Christopher Newport University. He can be reached at zhaochen.he@cnu.edu.
Republicans are much less concerned than Democrats about contracting the virus (Newport 2020). Given these differences, it is not surprising that Republicans feel more comfortable than Democrats about ending social distancing and reopening state economies (Skelley 2020). One of the main partisan divides is about mask wearing: Republicans believe wearing masks in public is much less important than Democrats believe (Pew Research Center 2020).

The effects of the coronavirus pandemic initially were felt most acutely in large urban centers, which tend to be populated mainly by Democratic Party identifiers. Therefore, differing partisan attitudes about the coronavirus well may have been a function of its differing geographical impact. However, partisan differences in attitudes about the virus remain as it spreads into more rural, Republicanleaning areas of the country (Blumenthal 2020). This most likely can be attributed to the messaging of political elites about the coronavirus. President Trump consistently downplayed the danger of the virus, and Republican governors were (with some exceptions) slower than their Democratic counterparts to institute shutdowns in an attempt to slow its spread (Brownstein 2020). This resulted in tensions in some states between Republican governors and Democratic mayors, who want more severe restrictions in their cities than the governors are willing to allow (Flynn and Iati 2020).

Although the partisan gap surrounding the coronavirus is one of the most visible manifestations of such a divide regarding health and safety issues, it is not unique. Research has shown that partisan divisions have influenced other health-related issues as well. For example, Democrats were more likely than Republicans 
to enroll in the state and federal insurance exchanges provided by the Affordable Care Act (Lerman, Sadin, and Trachtman 2017) and to use its private marketplace plans (Sances and Clinton 2019). Democratic and Republican physicians were shown to recommend different treatments for "politicized" health issues, such as abortion (Hersh and Goldenberg 2016). The evidence also suggests that between February 17 and March 7, 2020, also is available and is used in the following results. More details about these data are described by Warren and Skillman (2020).

Our primary independent variables are two measures of political affiliation: (1) the party of each state's governor; and (2) the Republican margin of victory, by county, in the 2016 general

\section{The effects of the coronavirus pandemic initially were felt most acutely in large urban centers, which tend to be populated mainly by Democratic Party identifiers. Therefore, differing partisan attitudes about the coronavirus well may have been a function its differing geographical impact.}

state human papillomavirus vaccine rates are associated with partisanship, with lower rates observed in states where the Republican Party vote share was higher in the 2016 presidential election (Suryadevara et al. 2019). Allcott et al. (2020), who also study the COVID-19 pandemic, found partisan trends in social distancing by differing beliefs between Democratic and Republican voters.

\section{DATA}

This article investigates the quantitative effects of partisanship on not only policy but also on individual behavior. The data used for this analysis are summarized in table 1 (Camobreco and He 2021). Figures for our primary dependent variable (i.e., mobility) were obtained through a noncommercial-use license with Descartes Labs, a private firm based in New Mexico that aggregates geospatial data. This variable, which allowed us to gauge the reduction in day-to-day activity related to the virus, can be viewed as a proxy for social distancing and other choices intended to mitigate pandemic risk. Descartes Labs uses commercially available mobile phone data to compute the maximum straight-line distance traveled by each user per day. The median value of this distance then is found for each US county, resulting in an absolute measure of how far individuals in the United States are moving. A relative measure, which recasts this value as a percentage of its median, by county, election. The second measure is defined as the difference between the percentage voting for Donald Trump and the percentage voting for Hillary Clinton. These data were available for every state except Alaska.

In establishing the partisan effect of COVID-19 compliance, it is important to control for the severity of the disease. Therefore, daily county-level data on new deaths and new confirmed cases were collected from Johns Hopkins University. These data fluctuate greatly and tend to spike on Fridays due to the reporting cycle; therefore, we smoothed them with a seven-day moving average. Additional controls, including population density and median household income, were obtained from the American Community Survey five-year estimates available from the US Census Department.

\section{FINDINGS}

The following analyses examine the partisan response of both political elites and the public to COVID-19.

\section{State-Level Lockdown Policy}

We first consider whether state policy related to the coronavirus differed based on political affiliation of either the voters or their elected officials. Figures 1 and 2 show that, prima facie, Democratic

Table 1

Data Sources

\begin{tabular}{|c|c|c|c|}
\hline Variable & Frequency & Geography & Source \\
\hline Relative Mobility & Daily & County & Descartes Labs \\
\hline \multicolumn{4}{|l|}{ Political Variables } \\
\hline 2016 Republican Victory Margin & 2016 & County & Kaggle Repository \\
\hline \multicolumn{4}{|l|}{ COVID-19 Indicators } \\
\hline Total Deaths & Daily & County & Johns Hopkins University \\
\hline Total Confirmed Cases & Daily & County & Johns Hopkins University \\
\hline \multicolumn{4}{|l|}{ Other Controls } \\
\hline Median Age & 2018 & County & ACS 5-Year Estimates \\
\hline Population Density & 2018 & County & ACS 5-Year Estimates \\
\hline Median Household Income & 2018 & County & ACS 5-Year Estimates \\
\hline Unemployment Rate & Monthly & County & US Bureau of Labor Statistics \\
\hline Percentage College Educated & 2018 & County & ACS 5-Year Estimates \\
\hline
\end{tabular}




\section{Figure 1}

Partisan Trends in Mobility and COVID-19 Risk
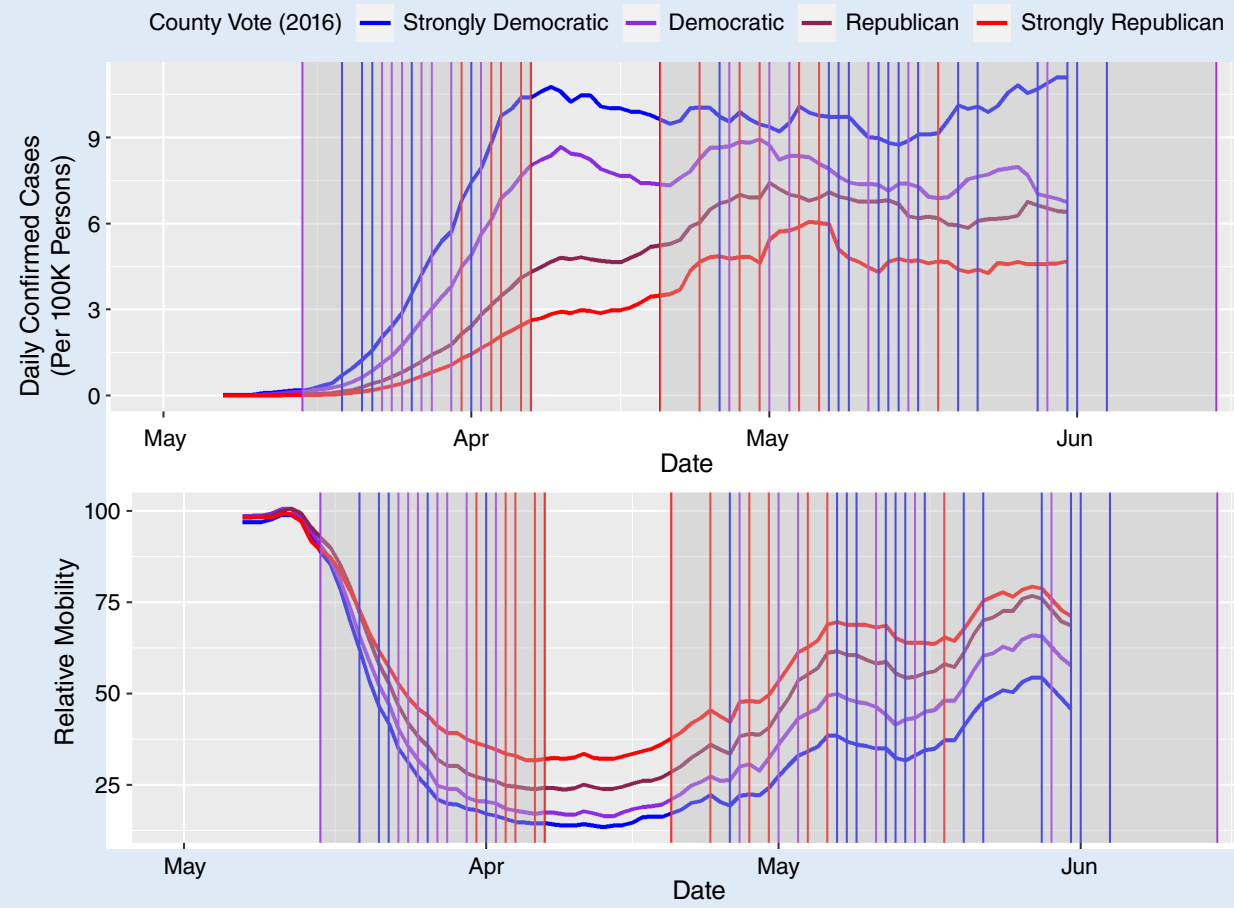

Notes: (Top) Mean daily new confirmed COVID-19 cases across US counties. (Bottom) Mean relative mobility, as measured by cell phone data, across US counties. Vertical lines represent a date when at least one state lockdown was declared, with color reflecting governor's party for state(s) declaring that day.

\section{Figure 2}

\section{Mobility Before and After the Lockdown (First COVID-19 Wave)}
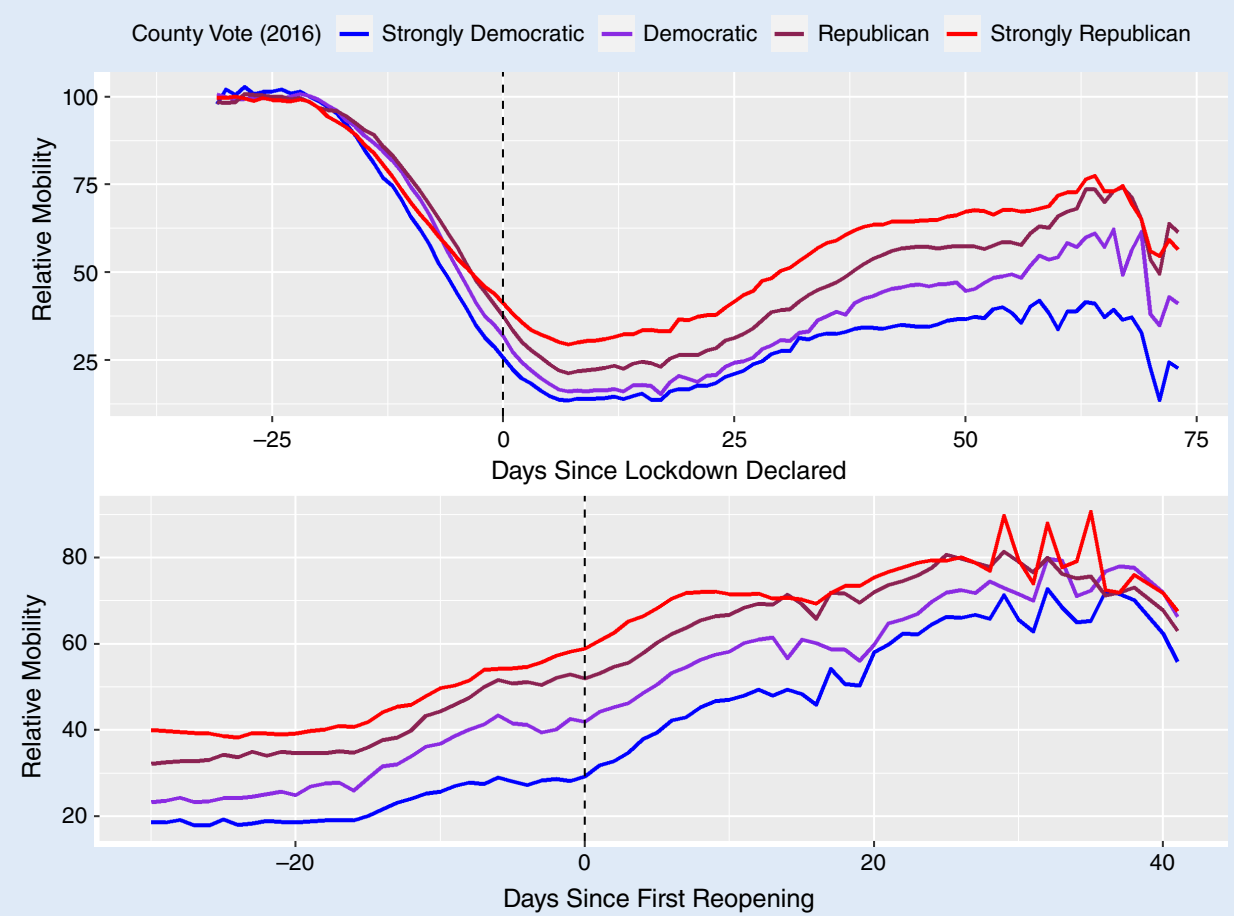

Notes: (Top) Mean mobility across US counties as a function of days since corresponding state lockdown. (Bottom) Analogous to the top panel but shows days since first partial lifting of lockdown orders. 
states declared lockdowns sooner, reopened later, and experienced a greater reduction in mobility than their Republican counterparts. Figure 1 (top) also confirms that COVID-19 infection rates were highest among these blue states. Without controlling for disease prevalence, it is impossible to establish whether this partisan effect is causal in nature. coefficients, which re-express the marginal effect of each variable in terms of its standard deviation, allowing effect sizes to be compared across explanatory variables. These figures show that even COVID-19 death rates, which were the closest to being significant after the governor's party, exhibit an effect less than half the size of the political variable.

\section{To summarize, the key public health indicator-COVID-19 infection rates-had little or no effect on state-level lockdown policy.}

Figure 3 plots the Republican margin of victory in the 2016 presidential election against each state's delay in reopening, which is defined as the number of days between peak COVID-19 (by daily cases) and when a state first began partial lifting of its lockdown mandate (assuming it had one). Total COVID-19 load, measured as per capita confirmed cases on June 15,2020 , is shown by the size of each datapoint. ${ }^{1}$ This shows that many Republican states reopened sooner than their Democratic counterparts, despite similar rates of infection. Figure 4 recasts these data by plotting coronavirus infection rates on the horizontal axis; again, we see evidence that red states tended to reopen with greater haste-especially across states with a relatively low disease burden.

Table 2 reports an ordinary least squares regression that integrates these factors controlling for disease prevalence, median age, population density, income, and education levels; the unit of observation is a single state. ${ }^{2}$ With these controls in place, only the Republican-governor variable had a statistically significant effect on reopening policy. Columns (2) and (4) display standardized
To summarize, the key public health indicator-COVID-19 infection rates-had little or no effect on state-level lockdown policy. Although this may seem stunning, the geographic distribution of the coronavirus, particularly in its first wave, was highly heterogenous. As late as mid-April 2020, even after the last lockdown had been declared, more than half of all states had yet to experience 100 confirmed deaths. In these states that were still unscathed by the coronavirus, it is perhaps more understandable that political attitudes-and the value judgments they implyplayed a larger role in setting policy.

\section{Compliance with Lockdown Orders}

These results show that governors' party affiliations strongly impacted COVID-19 policy at the state level. But what about the response of their constituents to that policy? Using the following two models, we investigate the partisan gap in how individuals behaved during lockdown.

For each US county, we computed mobility and COVID-19 rates, averaged over time, during and after its parent state's

Figure 3

Partisan Trends in Reopening Date

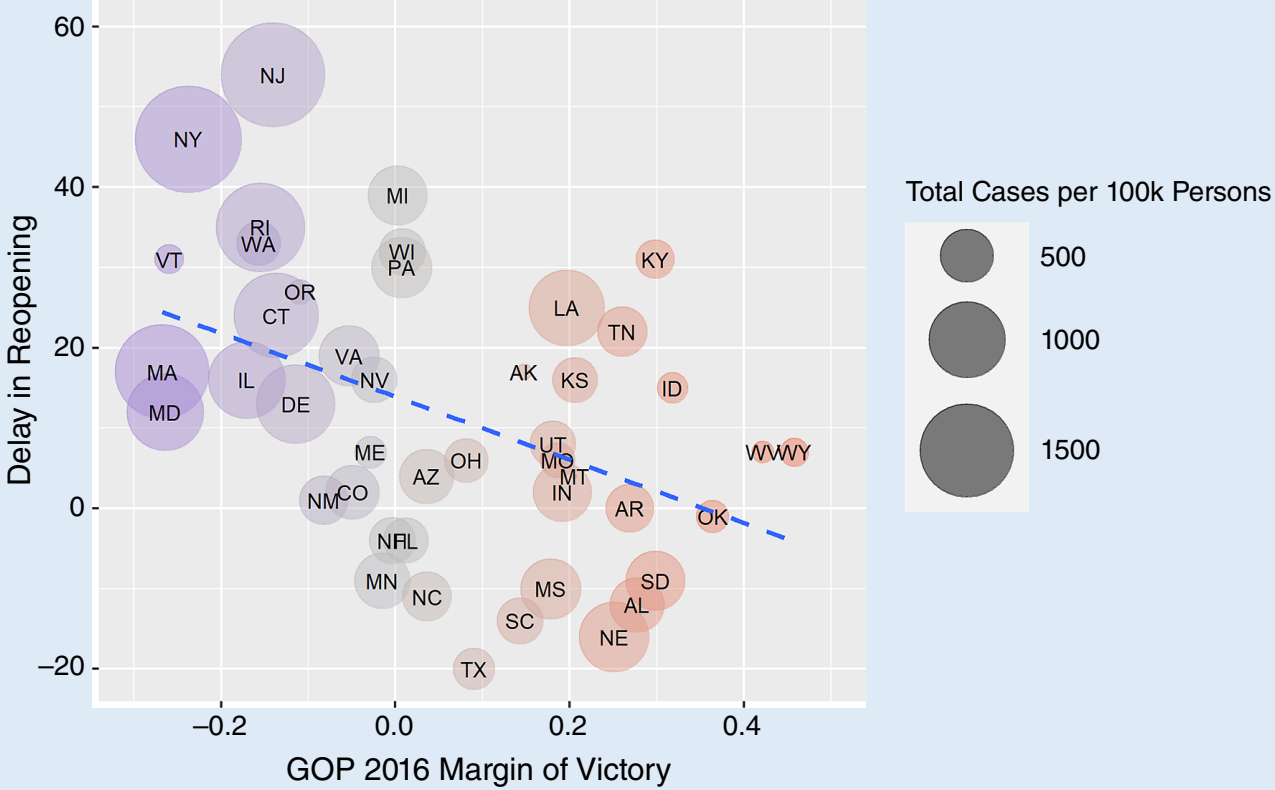

Notes: Republican states reopened more quickly, even compared to Democratic states with a similar disease burden. Delay in reopening is defined as the number of days between peak COVID-19 intensity and first partial lifting of a state's lockdown order. A negative value reflects a state reopening prior to peak COVID-19. Peak COVID-19 is defined as the date with the most daily new confirmed cases before June 15, 2020. Size of the circles reflects total cases per 100k persons as of June 15, 2020. 


\section{Figure 4}

\section{Partisan Effect Is Strongest in Low COVID-19 States}

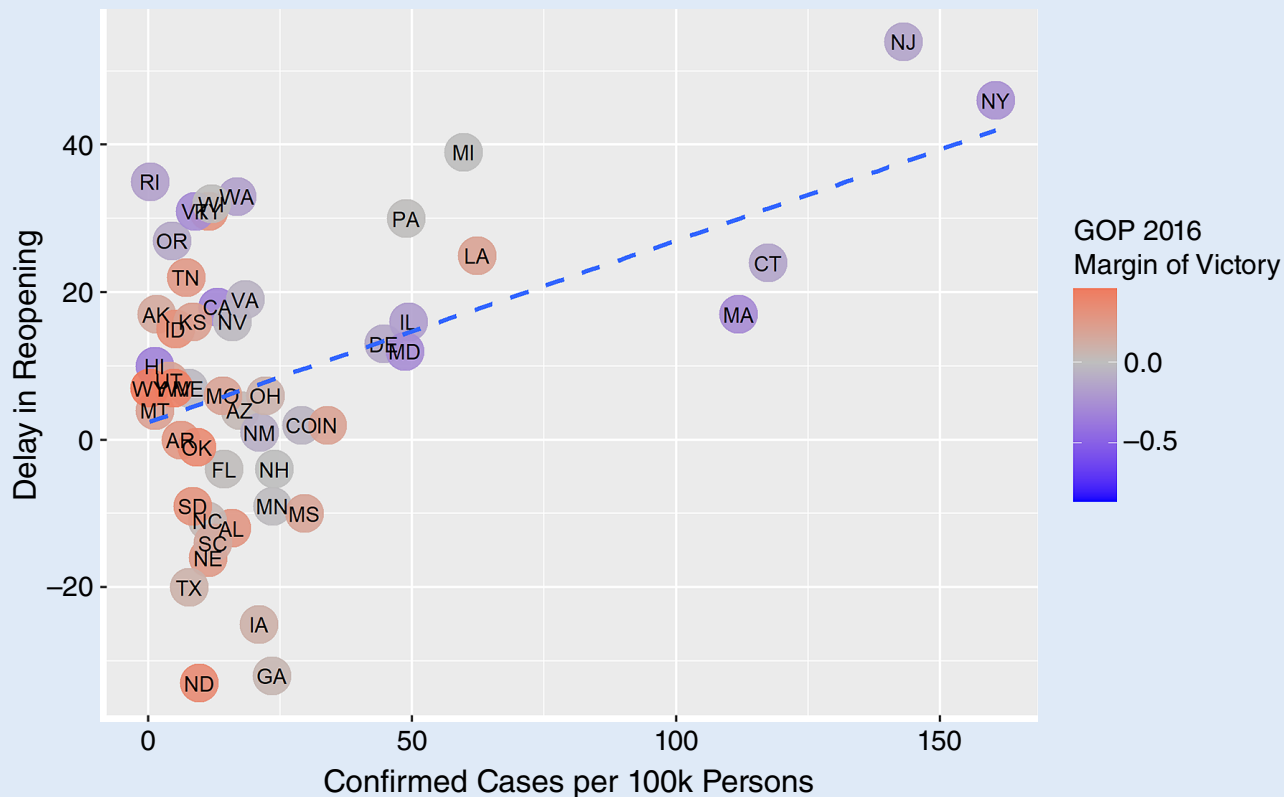

Notes: Apart from largely Democratic northeastern states, COVID-19 burden in the United States was relatively low during the first wave. The partisan effect was particularly noticeable among these less-affected states.

lockdown period. We then regressed mobility on the 2016 Republican margin of victory and COVID-19 burden-the same crosssectional controls as in the previous model (now at the county level)-as well as a state's fixed effect. ${ }^{3}$

The results are shown in table 3, with raw and standardized coefficients in alternating columns. These findings show that political affiliation also had a strong role in guiding individual behavior concerning the coronavirus. We found that red counties maintained significantly higher levels of mobility in both periods, even after controlling for population density and other characteristics. Examination of the standardized coefficients shows that partisanship was the single-most important predictor of mobility during the lockdown period and the third most important subsequently, second only to income and education levels. lockdown is modeled with a dummy variable indicating if a county was subject to lockdown on a specific day. We also interacted political affiliation with lockdown status and the party of the state's governor to determine whether the party effect was moderated by either of these factors.

This specification also includes the county-level unemployment rate, as reported monthly by the US Bureau of Labor Statistics. By incorporating this measure into our model, our estimates represent the effect of partisanship on social distancing, control for COVID-19 rates, and controlling for the economic circumstances within a given county that same month.

The results shown in table 4 represent our best estimates, given the available data. ${ }^{4}$ We found that, in relative terms, partisanship is the second strongest driver of mobility reduction after median household income. COVID-19 burden finally appears to be

\section{Our model predicts that mobility in a typical Republican county under lockdown is comparable to a typical Democratic county without a lockdown, even after controlling for COVID-19 prevalence, local economic conditions, population density, and other demographic characteristics.}

\section{Panel Regressions}

These specifications average our mobility figures over the lockdown period, reducing our dataset to a county cross section. As an alternative, we used our full panel, with daily data for both mobility and COVID-19 burden in each US county. This expanded our sample size by several orders of magnitude and allowed for a more precise estimate of the effects. Here, the impact of the significant in this specification, although its effect is several orders of magnitude smaller than the previously mentioned variables. Population density and age also are significant, with the expected signs; however, again, they are significantly weaker than partisanship. 5

Figures 5 and 6 visualize the two interaction effects estimated in table 4 . We found that the effects of political affiliation were 
Table 2

Effects of Partisanship on State-Level COVID-19 Policy

\begin{tabular}{|c|c|c|c|c|}
\hline & & ependent Varia & eopening (Days) & \\
\hline & Raw Coefficient & Standardized & Raw Coefficient & Standardized \\
\hline & (1) & (2) & (3) & (4) \\
\hline Republican Governor & $-17.906^{* * *}$ & $-0.469 * * *$ & $-17.128^{* * *}$ & $-0.449 * * *$ \\
\hline & $p=0.002$ & $p=0.002$ & $p=0.002$ & $p=0.002$ \\
\hline 2016 Republican Victory Margin & -1.036 & -0.011 & -0.997 & -0.010 \\
\hline & $p=0.957$ & $p=0.957$ & $p=0.958$ & $p=0.958$ \\
\hline Confirmed Cases per 100k & 0.002 & 0.041 & & \\
\hline & $p=0.837$ & $p=0.837$ & & \\
\hline Deaths per 100k & & & 0.116 & 0.214 \\
\hline & & & $p=0.179$ & $p=0.179$ \\
\hline Median Age & 0.986 & 0.122 & 1.013 & 0.125 \\
\hline & $p=0.403$ & $p=0.403$ & $p=0.354$ & $p=0.354$ \\
\hline Population Density & 0.020 & 0.274 & 0.013 & 0.179 \\
\hline & $p=0.228$ & $p=0.228$ & $p=0.308$ & $p=0.308$ \\
\hline Median Household Income & 0.0004 & 0.203 & 0.0004 & 0.218 \\
\hline & $p=0.398$ & $p=0.398$ & $p=0.339$ & $p=0.339$ \\
\hline Percentage College & -0.745 & -0.199 & -0.880 & -0.235 \\
\hline & $p=0.420$ & $p=0.420$ & $p=0.324$ & $p=0.324$ \\
\hline Constant & -25.343 & 0.000 & -25.130 & 0.000 \\
\hline & $p=0.654$ & $p=0.654$ & $p=0.631$ & $p=0.631$ \\
\hline Observations & 50 & 50 & 50 & 50 \\
\hline $\mathrm{R}^{2}$ & 0.431 & 0.431 & 0.455 & 0.455 \\
\hline Adjusted $R^{2}$ & 0.336 & 0.336 & 0.364 & 0.364 \\
\hline
\end{tabular}

Notes: ${ }^{*} p<0.1 ;{ }^{* *} p<0.05 ;{ }^{* *} p<0.01$

Table 3

Effects of Partisanship on Social Distancing (County Level)

Dependent Variable: Relative Mobility

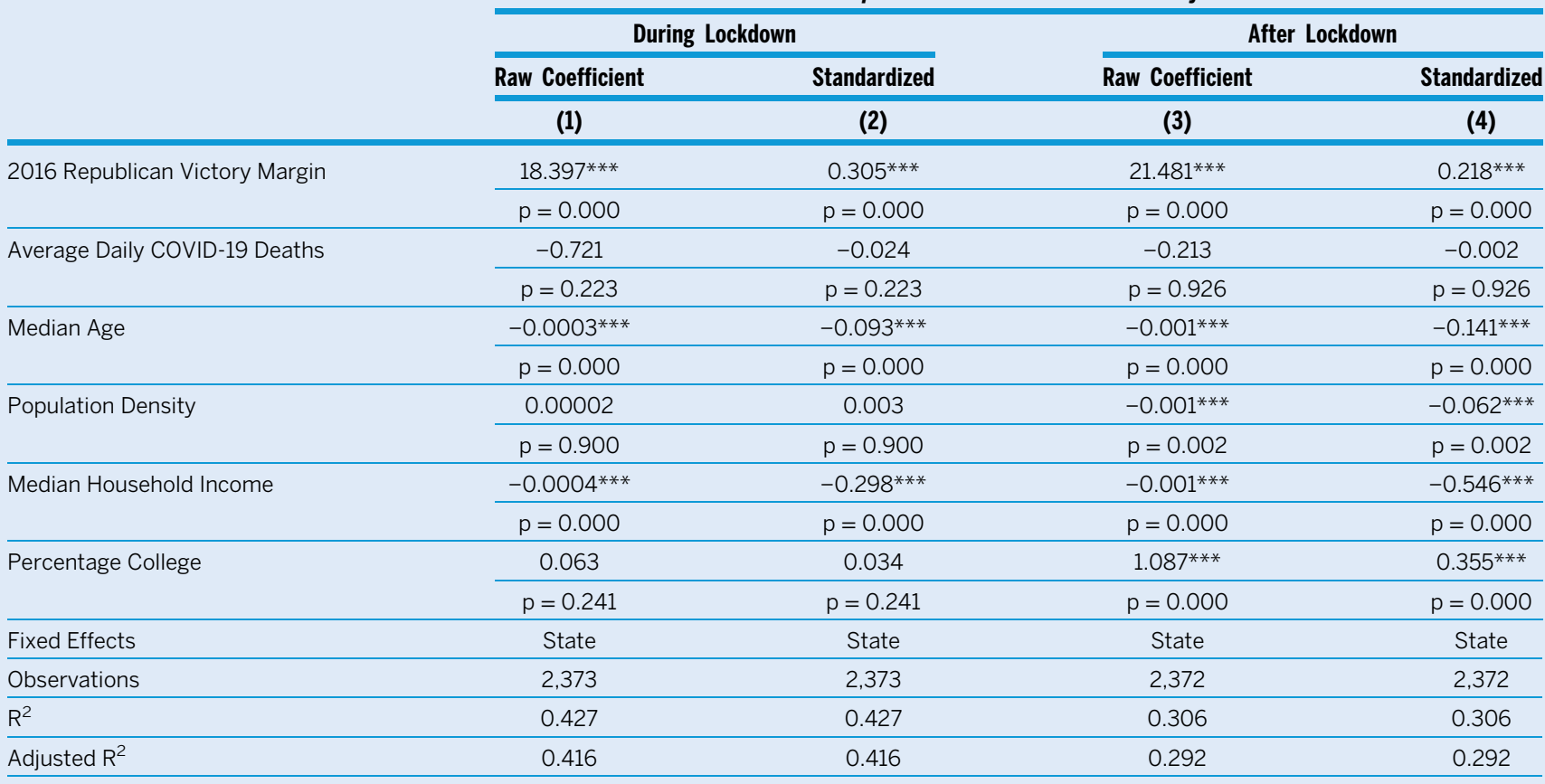

Notes: ${ }^{*} p<0.1 ;{ }^{* *} p<0.05 ;{ }^{* *} p<0.01$. 
Table 4

Effects of Partisanship on Social Distancing (Panel Specification)

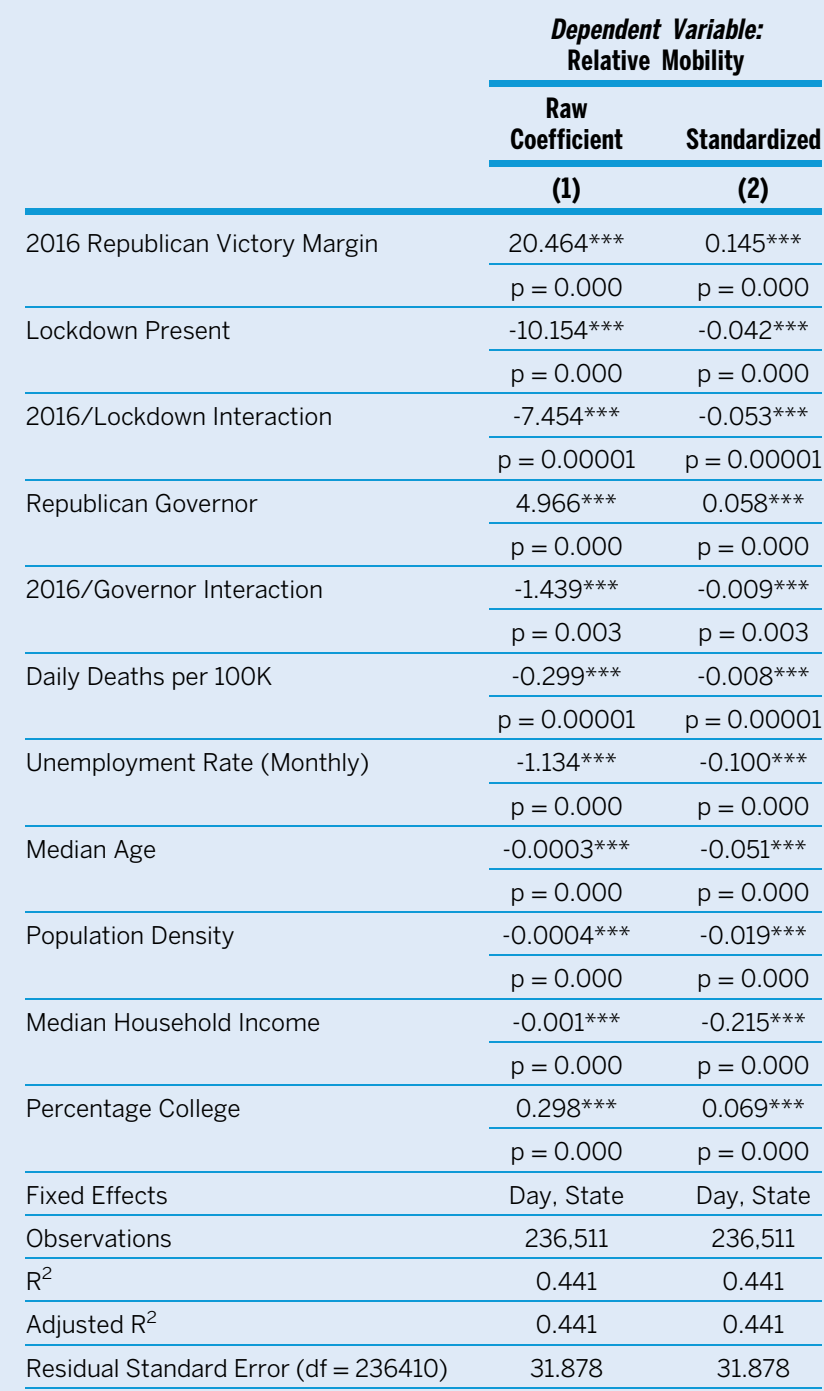

Notes: ${ }^{*} \mathrm{p}<0.1 ;{ }^{* *} \mathrm{p}<0.05 ;{ }^{* *} \mathrm{p}<0.01$

attenuated during lockdown. This is unsurprising given that voters from both parties would be subject to the state restrictions. The effect of party was enhanced by a Republican governor; however, this effect, although statistically significant, was weak in absolute terms.

Overall, the estimated effect of partisanship on mobility is extremely strong. Consider a simple linear prediction using the

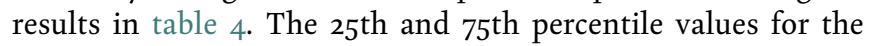
Republican margin of victory in 2016 are 0.15 and 0.55 , respectively-a difference of 0.40 . Using the estimate in table 4 , column (1), an increase in the Republican 2016 margin of victory by this magnitude would imply an increase in mobility by roughly $8 \%$ relative to pre-COVID-19 levels. This is greater than the estimated $7.45 \%$ reduction resulting from a lockdown. That is, our model predicts that mobility in a typical Republican county under lockdown is comparable to a typical Democratic county without a lockdown, even after controlling for COVID-19
Figure 5

\section{Interaction Between Party and Other Factors}

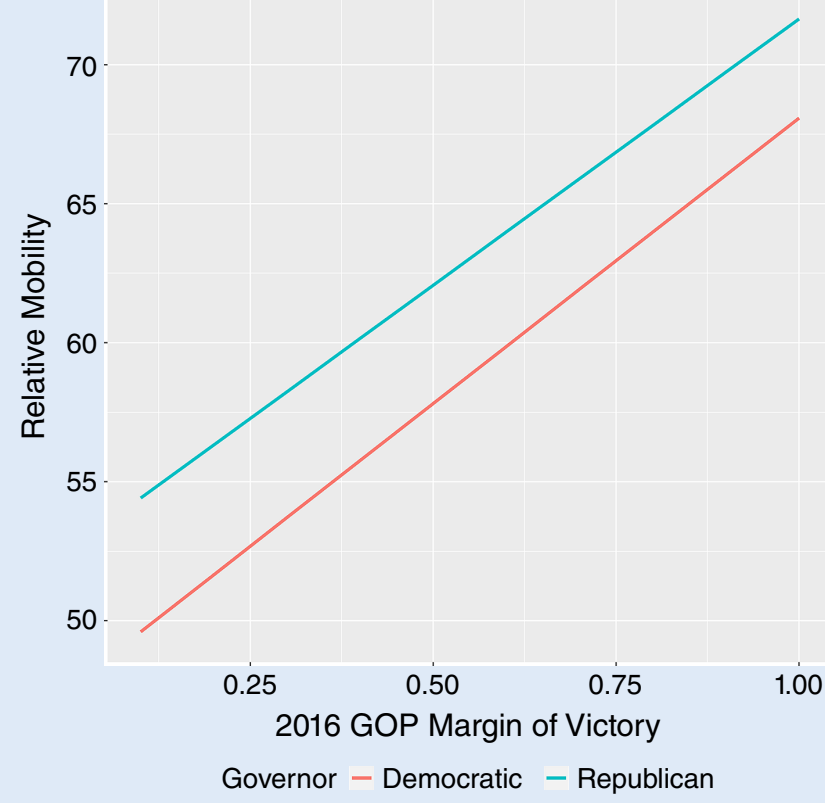

Notes: Interaction plots were generated using linear prediction on the model in table 4. (Left) The partisan effect was attenuated during a state's lockdown period. (Right) The party of a state's governor did not seem to significantly enhance the partisan gap.

Figure 6

Interaction Effects: Party and Lockdown Status

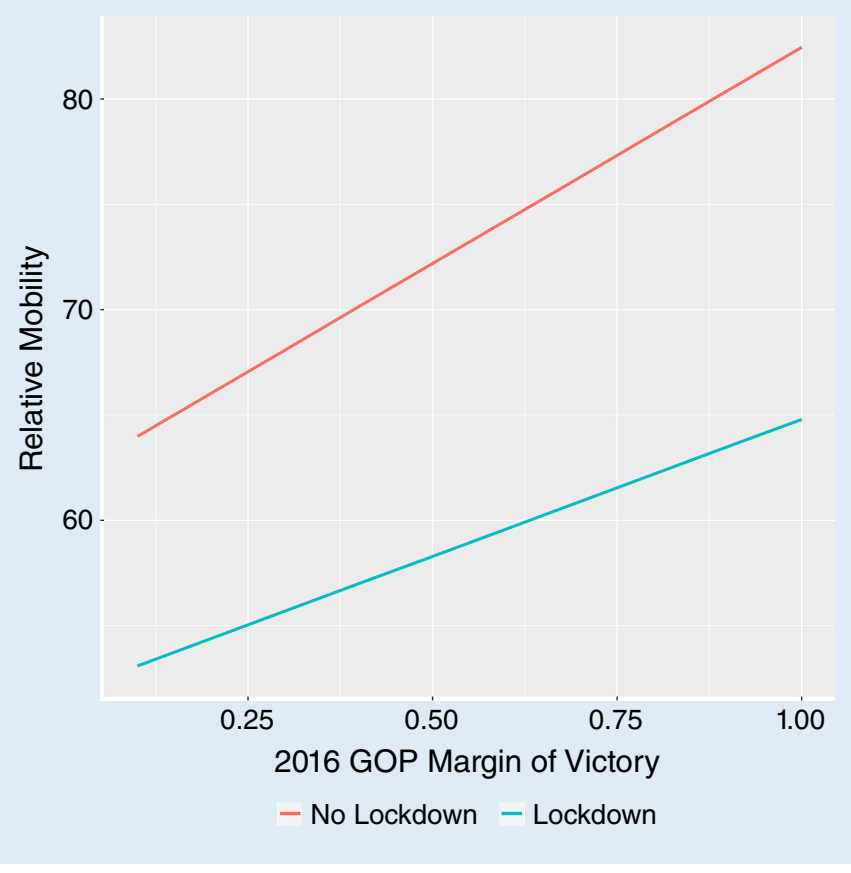

prevalence, local economic conditions, population density, and other demographic characteristics. 


\section{DISCUSSION}

Our results indicate that partisanship was a strong predictor of county-level mobility during the COVID-19 pandemic, even when accounting for the severity of the coronavirus outbreak in each county. The relationship between partisanship and mobility was weakened during the period in which each county experienced a shutdown but remained significant. But why should partisanship have such a significant impact on an ostensibly apolitical issue? One possibility is that the coronavirus was initially partisan, spreading rapidly first through high-density Democratic-leaning counties, leaving lower-density Republican-leaning counties largely untouched. Yet, our research shows that this is not the case; even when controlling for local COVID-19 burden, the partisan effect remains robust.

Our findings suggest several possible explanations. The first factor is that the perceived seriousness of the coronavirus threat was a function of partisanship. Republican governors did not take it as seriously as their Democratic counterparts, as evidenced by the early lifting of lockdowns shown in table 2. Studies suggest that this signal from their party leaders led Republicans to take the coronavirus less seriously across a bevy of self-reported behaviors (Beauchamp 2020; Fleming-Wood, Margalit, and Schaffner 2020). Furthermore, differing partisan attitudes about the seriousness of the pandemic reflects distinctive party views on science in general. Public health experts, including Dr. Anthony Fauci, expressed concern about the pandemic even before March 2020, but research shows that Republicans are more likely than Democrats to reject the recommendations of scientists (Blank and Shaw 2015).

Second, partisan differences in mobility patterns during the pandemic also may have been driven by the differing priorities associated with Democratic and Republican Party identifiers. For example, during the 2020 presidential-election campaign, Democrats believed that the coronavirus was the most important issue facing the nation, whereas Republicans believed it was the economy (Seven Letter Insight 2020). The priority placed on the economy by Republicans is consistent with a reluctance to curtail their movements during the pandemic. However, our findings show that partisanship is still significant even after controlling for local economic conditions, which indicates that Democrats and Republicans facing similar economic risk nevertheless behaved differently. This suggests that to the extent the economy motivated the choices of Republicans, these choices were based more on sociotropic than pocketbook considerations. That is, Republicans appeared to be more concerned about the state of the economy as a whole rather than their own personal financial situation.

Third, research has shown that one of the core political values shaped by partisanship is limited government (Goren 2005). Thus, the Republican resistance to shutdown orders could have been associated with a belief among Republicans that such orders amounted to governmental overreach and a violation of individual freedom. Regardless of what drove partisan differences in mobility patterns, our findings are a stark reminder that partisanship can have a significant impact on issues that are not obviously political.

\section{DATA AVAILABILITY STATEMENT}

Replication materials are available on Harvard Dataverse at https://doi.org/10.7910/DVN/GGMWoH. "

\section{NOTES}

1. This analysis pertains to the first wave of coronavirus infection, from the beginning of March through June 15, 2020.

2. The estimation equation for the results in table 2 is $\mathrm{MOB}_{\mathrm{i}}=$ bo $+\mathrm{b}_{1} \mathrm{GOPMARG}_{\mathrm{i}}+$ b2 COVID-19 $i+$ bCONTROLS $_{i}+e_{i} ; i=1 \ldots n$ states.

3. The estimation equation for the results in table 3 is $\mathrm{MOB}_{\mathrm{i}}=$ bo $+\mathrm{b}_{1} \mathrm{GOPMARG}_{\mathrm{i}}+$ b2 COVID-19 $i+$ bCONTROLS $_{i}+$ FE $_{\text {state }}+e_{i}, i=1 \ldots n$ counties

4. The estimation equation for the results in table 4 is $\mathrm{MOB}_{\mathrm{it}}=$ bo $+\mathrm{b}_{1} \mathrm{GOPMARG}_{1}$ $+\mathrm{b}_{2}$ COVID-19it + bCONTROLS $_{\mathrm{i}}+\mathrm{FE}_{\mathrm{t}}+\mathrm{e}_{\mathrm{i}}, \mathrm{i}=1 \ldots \mathrm{n}$ counties, $\mathrm{t}=1 \ldots \mathrm{n}$ days.

5. For completeness, we also implemented a version of the model with a state-level fixed effect and clustered standard errors using the method of Cameron, Gelbach, and Miller (2011). This specification is included in the appendix (table A1).

\section{REFERENCES}

Allcott, Hunt, Levi Boxell, Jacob Conway, Matthew Gentzkow, Michael Thaler, and David Yang. 2020. "Polarization and Public Health: Partisan Differences in Social Distancing during the Coronavirus Pandemic." https://papers.ssrn.com/sol3/ papers.cfm?abstract_id $=3570274$.

Beauchamp, Zack. 2020. "How Polarization Shaped Americans' Responses to Coronavirus, in One Chart." Vox, March 23. www.vox.com/2020/3/23/21190997/ coronavirus-COVID-19-trump-polarization-data.

Blank, Joshua M., and Daron Shaw. 2015. "Does Partisanship Shape Attitudes toward Science and Public Policy? The Case for Ideology and Religion." Annals of the American Academy of Political and Social Science. https://

doi.org/10.1177/0002716214554756.

Blumenthal, Mark. 2020. "The Spread of Coronavirus to Red America Is Not Shifting Opinions." YouGov, June 9. https://today.yougov.com/topics/politics/articlesreports/2020/06/o9/spread-coronavirus-red-america-analysis.

Brownstein, Ronald. 2020. "Red and Blue America Aren't Experiencing the Same Pandemic." The Atlantic, March 20. www.theatlantic.com/politics/ archive/2020/03/how-republicans-and-democrats-think-aboutcoronavirus/608395.

Cameron, A. Colin, Jonah B. Gelbach, and Douglas L. Miller. 2011. "Robust Inference with Multiway Clustering." Journal of Business \& Economic Statistics 29 (2): $238-49$.

Camobreco, John F., and Zhaochen He. 2021. "Replication Data for: The Party-Line Pandemic: A Closer Look at the Partisan Response to COVID-19 Shutdown Orders." Harvard Dataverse https://doi.org/10.7910/DVN/GGMWoH.

Fleming-Wood, Bennett, Yonatan Margalit, and Brian Schaffner. 2020. "The Emergent Partisan Gap in Social Distancing.” www.dataforprogress.org/ blog/2020/6/21/the-emergent-partisan-gap-in-social-distancing.

Flynn, Meghan, and Marisa Iati. 2020. "Georgia Gov. Brian Kemp Sues Atlanta over Mask Requirement as Coronavirus Surges in the State." Washington Post, July 16. www.washingtonpost.com/nation/2020/o7/16/kemp-georgia-maskmandates.

Funk, Cary, and Alec Tyson. 2020. "Partisan Differences over the Pandemic Response Are Growing." Scientific American, May 3o. https://blogs. scientificamerican.com/observations/partisan-differences-over-the-pandemicresponse-are-growing.

Goren, Paul. 2005. "Party Identification and Core Political Values." American Journal of Political Science 49 (4): 882-97.

Green, Donald P., Bradley Palmquist, and Eric Schickler. 2002. Partisan Hearts and Minds: Political Parties and the Social Identities of Voters. New Haven, CT: Yale University Press.

Hersh, Eitan D., and Matthew N. Goldenberg. 2016. "Democratic and Republican Physicians Provide Different Care on Politicized Health Issues." Proceedings of the National Academy of Sciences 113 (42): 11811-16.

Lerman, Amy E., Meredith L. Sadin, and Samuel Trachtman. 2017. "Policy Uptake as Political Behavior: Evidence from the Affordable Care Act." American Political Science Review 111 (4): 755-70.

Newport, Frank. 2020. "The Partisan Gap in Views of the Coronavirus.” Gallup, May 15. https://news.gallup.com/opinion/polling-matters/311087/partisan-gap-viewscoronavirus.aspx.

Pew Research Center. 2020. "Republicans, Democrats Move Even Further Apart in Coronavirus Concerns." June 25. www.pewresearch.org/politics/2020/06/25/ republicans-democrats-move-even-further-apart-in-coronavirus-concerns.

Sances, Michael W., and Joshua D. Clinton. 2019. "Who Participated in the ACA? Gains in Insurance Coverage by Political Partisanship." Journal of Health Politics, Policy, and Law 44 (3): 349-79. 
Seven Letter Insight. 2020. "2020 Voter Priorities Survey." www.politico.com/f/?id= ooooo175-f 4 af-d692-a975-fcffob6500oo.

Skelley, Geoffrey. 2020. "The Gap Between Democrats and Republicans Is Growing on the Coronavirus Crisis." fivethirtyeight.com, May 22. https://

fivethirtyeight.com/features/democrats-and-republicans-are-increasingly-spliton-the-coronavirus-crisis.
Suryadevara, Manika, Cynthia A. Bonville, Donald A. Cibula, Joseph B. Domachowske, and Amar C. Suryadevara. 2019. "Associations Between Population-Based Voting Trends During the 2016 US Presidential Election and Adolescent Vaccination Rates.” Vaccine 37 (9): 1160-67.

Warren, Michael S., and Samuel W. Skillman. 2020. "Mobility Changes in Response to COVID-19." March 31. https://arxiv.org/abs/2003.14228.

\section{APPENDIX}

\section{Table A1}

County-Level Regressions with State Fixed Effect and Clustered Standard Errors

\section{Dependent Variable:} Relative Mobility

Raw Coefficient

\begin{tabular}{lc}
\hline 2016 Republican Victory Margin & $13.002^{* * *}$ \\
\hline Lockdown Present & $p=0.000$ \\
\hline Daily Deaths per 100K & $-7.646^{*}$ \\
\hline Unemployment Rate (Monthly) & $-0.273^{*}$ \\
\hline Median Age & $p=0.072$ \\
\hline Population Density & $-0.858^{* * *}$ \\
\hline Median Household Income & $p=0.00000$ \\
\hline Percentage College & $-0.0003^{* * *}$ \\
\hline Fixed Effects & $p=0.005$ \\
\hline Observations & -0.0002 \\
\hline$R^{2}$ & $-0.001^{* * *}$ \\
\hline Adjusted R & $p=0.000$ \\
\hline Residual Standard Error & $0.274^{* * *}$ \\
\hline & $p=0.004$ \\
\hline
\end{tabular}

Notes: ${ }^{*} p<0.1 ;{ }^{* *} p<0.05 ;{ }^{* *} p<0.01$ 